\title{
DA DESVALORIZAÇÃO DA JURISPRUDÊNCIA PELO SUPREMO TRIBUNAL FEDERAL: A FUNDAMENTAÇ̃̃̃O PERSONALISTA E A AUSÊNCIA DA SÍNTESE DO ESTADO DE JURISPRUDÊNCIA
}

\section{DEPREZZAMENTO DELLA GIURISPRUDENZA DALLA CORTE SUPREMA: MOTIVAZIONE PERSONALISTA E LA MANCANZA DI SINTESI DI STATO DELLA GIURISPRUDENZA}

\author{
${ }^{1}$ Tarcísio Maciel Chaves de Mendonça \\ ${ }^{2}$ Michel Wencland Reiss
}

\section{RESUMO}

O presente artigo tem como objetivo demonstrar que o Supremo Tribunal Federal nega sua colegialidade, adotando um modelo personalista de decisão. Os membros da Suprema Corte não tomam a decisão debatendo, no colegiado, os fundamentos de seus votos. Na sessão colegiada, a decisão é tomada pela simples somatória dos votos. O presente trabalho ainda irá evidenciar que o Supremo Tribunal Federal não trata adequadamente seus próprios precedentes. A jurisprudência da Suprema Corte não é usada pelo próprio tribunal para construir suas futuras decisões, mas somente para legitimá-las. Para demostrar nossa hipótese, analisamos a questão de ordem levantada sobre o desmembramento do inquérito $\mathrm{n}$ 2245 e a relativização da súmula 691 do STF.

Palavras-chave: Supremo tribunal federal, Jurisprudência, Fundamentação personalista

\section{RIASSUNTI}

Questo articolo si propone di dimostrare che la Corte Suprema nega la sua collegialità, adottando uno stile personalista di decisione. I membri della Corte Suprema non decidono di discutere, in collegiata, i fondamenti della loro voto. Alla decisione collegiata seduta è presa da semplice aggiunta di voti. Tale studio dovrà anche dimostrare che la Corte Suprema non ha adeguatamente affrontare i loro precedenti. La giurisprudenza della Corte Suprema non è utilizzata dal giudice stesso a costruire le sue decisioni future, ma solo per legittimare loro. Per dimostrare la nostra ipotesi, abbiamo analizzato la mozione d'ordine per la rottura della investigazione n 2245 e la relatività della sintesi di precedente n. 691 della Corte Suprema.

Parole chiave: Corte suprema, Giurisprudenza, motivazione personalista

\footnotetext{
${ }^{1}$ Doutorando em Direito pela Universidade Federal de Minas Gerais - UFMG, Minas Gerais (Brasil) E-mail: tarcisiomcmendonca@yahoo.com.br

${ }^{2}$ Doutorando em Direito pela Pontifícia Universidade Católica do Rio de Janeiro - PUC/RJ, Rio de Janeiro (Brasil).

E-mail: michel@mrladvocacia.com.br
} 


\section{INTRODUÇÃO}

O presente trabalho pretende demonstrar como o Supremo Tribunal Federal não valoriza a sua própria jurisprudência.

Num primeiro momento, serão feitas considerações acerca de como o STF se utiliza, segundo Carlos Ari Sundfeld e Henrique Motta Pinto, de "fundamentação personalista”. Em síntese, afirmam que o Supremo Tribunal Federal realiza julgamentos colegiados de forma individualizada, ou seja, sem deliberação entre os ministros. Nesse contexto, será apresentado o "projeto de uma corte deliberativa" de Conrado Hübner Mendes, que tece considerações críticas acerca da forma de tomadas de decisões pelo STF.

Serão ainda discutidas as observações de Sundfeld e Pinto sobre o que denominam "ausência da síntese do estado da jurisprudência", ou seja, da ausência de tratamento sistematizado dos precedentes pelo STF e as consequências disso.

Após tais considerações iniciais, serão descritas situações que demonstram concretamente as constatações de Sundfeld e Pinto e ainda de Mendes.

Será demonstrado que, nos casos de foro por prerrogativa de função no Supremo Tribunal Federal, há regra no Código de Processo Penal que atrai a competência para o STF com relação aqueles que não possuem tal foro, havendo conexão ou continência - apesar de existir norma que permite o desmembramento facultativo. Entretanto, a jurisprudência entende pelo desmembramento. Por outro lado, por ocasião do julgamento de questão de ordem no Inquérito $2.245^{1}$, o Supremo Tribunal Federal contrariou seus precedentes e decidiu pela reunião dos quarenta denunciados numa só ação.

Também será abordada a Súmula 691 do STF, que não permite impetração de habeas corpus no Supremo contra indeferimento de liminar. Não obstante, são incontáveis os precedentes que ignoram a Súmula, o que será objeto de análise neste estudo com base em considerações de Noel Struchiner acerca das generalizações e da seriedade (ou não) das regras.

Tais situações concretas servirão para demonstrar a "fundamentação personalista" e ainda a "ausência da síntese do estado da jurisprudência" no âmbito do Supremo Tribunal Federal.

\footnotetext{
${ }^{1}$ Trata-se do Inquérito que culminou, após oferecimento e recebimento de denúncia, com a Ação Penal 470, que ficou conhecida pela alcunha de "mensalão". Entretanto, para que não se abandone a terminologia técnica, tal caso será tratado neste estudo como Inquérito 2.245, ou ainda como AP 470, a depender da fase procedimental a ser considerada.
} 


\section{A "FUNDAMENTAÇÃO PERSONALISTA" E A "AUSÊNCIA DO ESTADO DA JURISPRUDÊNCIA” NO STF.}

Não se pode negar a grande importância da jurisprudência como fonte do Direito. Mesmo em ordenamentos jurídicos baseados no sistema romano-germânico, a jurisprudência tem papel de destaque. Ao analisar esse sistema, afirma René David: "para julgar a importância que têm, na elaboração do direito, as decisões judiciárias, é necessário [...] duvidar das fórmulas feitas que, na intenção de sublinhar o exclusivismo a lei, recusam a natureza de fonte do de direito à jurisprudência”. (2002, p. 147). ${ }^{2}$

Por outro lado e segundo Sundfeld e Pinto, "o estudo do Direito no Brasil costuma menosprezá-la [a jurisprudência]" (2012, p. 20). Tal menosprezo também ocorre no âmbito do Supremo Tribunal Federal, que não valoriza a jurisprudência brasileira - nem mesma aquela que o próprio STF cria, segundo lição dos mencionados autores (2012, p. 23).

Um aspecto que chama atenção nesse processo de desvalorização da jurisprudência brasileira é o que Sundfeld e Pinto denominam "fundamentação personalista" (2012, p. 24). Os julgamentos colegiados são feitos de forma individualizada, por mais paradoxal que possa parecer. A “fundamentação personalista” é assim definida por Sundfeld e Pinto:

\footnotetext{
Uma característica presente na prática do STF é a de decidir por meio de votos que se limitam a expor o resultado e os fundamentos individuais de cada julgador. Não se percebe nos acórdãos do Tribunal uma preocupação de proferir resultado acompanhado das razões colegiadas que o embasem. Antes, o que há são peças argumentativas individuais, com frequentes variações na fundamentação, que não costumam tratar dos mesmos pontos, especialmente quando divergem. É comum que a leitura dos acórdãos revele arrazoados argumentativos construídos a partir de premissas diferentes e independentes, com trajetos apartados e baixo grau de interação entre os votos. (SUNDFELD; PINTO, 2012, p. 24).
}

A conclusão dos autores é, basicamente, que prevalece a argumentação individual sobre a coletiva (2012, p. 24).

\footnotetext{
${ }^{2}$ No caso da Common Law, a jurisprudência tem relevância ainda maior. David afirma expressamente que se trata da "principal fonte do direito inglês" (2002, p. 416). Já com relação ao Estado Unidos, afirma que se trata de "um direito essencialmente jurisprudencial", como ocorre na Inglaterra (2002, p. 477). Entretanto, apresenta algumas diferenças entre o tratamento da jurisprudência pelos dois países (2002, p. 478-484).
} 
Tal posição guarda consonância com aquela defendida por Mendes ao propor um "projeto de uma corte deliberativa" (2012, p. 53), criticando o funcionamento do Supremo Tribunal Federal. ${ }^{3}$ Tal autor defende o controle constitucional por juízes não eleitos em

fóruns deliberativos singulares. Seriam, em outras palavras, espaços que privilegiam o argumento à contagem de votos, foros decisórios que se caracterizam, essencialmente, pelo esforço de persuadir e abertura a ser persuadido por meio de razões imparciais $(2012$, p. 54$){ }^{4}$

Acrescenta ainda Mendes que são raros os casos de cortes pelo mundo em que a decisão é tomada como ocorre no Supremo Tribunal Federal, com uma simples contagem isolada de posicionamento dos ministros, o que acaba por gerar uma "colcha de retalhos - decisões individuais coladas lado a lado, que não conversam entre si” (2012, p. 66-67). Mendes defende uma proposta que parte da "plausibilidade de que a decisão tomada por meio de deliberação gere melhor resultado" (2012, p. 68). ${ }^{5}$

No mesmo sentido é a posição defendida por Sundfeld e Pinto ao afirmarem que "falta, atualmente, um trabalho mais intenso de deliberação colegiada, que permita a formação e a comunicação dos jurisdicionados das razões da Corte que informam suas decisões" (2012, p. 26). ${ }^{6}$

No que interessa ao presente estudo, há outro problema além da "fundamentação personalista". Sundfeld e Pinto afirmam que o STF não trata de forma adequada a jurisprudência, nem mesmo aquela criada pelo próprio Tribunal (2012, p. 29). Isso porque os precedentes do STF até são mencionados nos julgamentos, mas “o que falta, atualmente, é o tratamento sistemático, orgânico, completo, da jurisprudência na fundamentação de novas decisões" (2012, p. 30). É o que rotularam como "ausência da síntese do estado da jurisprudência" (2012, p. 29), que pode ser explicada da seguinte maneira:

\footnotetext{
3 Segundo o autor, o referido artigo "busca brevemente apresentar partes do argumento de minha tese de Doutorado em Filosofia do Direito, defendida no ano de 2011 na Escola de Direito da Universidade de Edimburgo sob o título Deliberative Performance of Constitucional Courts, e aplicar tais argumentos ao estilo decisório do STF" (2012, p. 53).

5 Itálico no original.

5 Entretanto, Mendes reconhece que a sua proposta não se esgota na deliberação, eis que se exige ainda o comprometimento "com a boa decisão substantiva que se expressa, quando possível e desejável, por meio de uma única voz ou, quando justificável, em múltiplas vozes, conquanto sejam responsivas e precedidas por contestação pública e interação colegiada" (2012, p. 68-69). Ou seja, exatamente o que não se percebe no Supremo Tribunal Federal.

6 Itálico no original. Continuam os autores: "Nele [no STF], falta espaço para que os ministros formem sua conviç̧ão de maneira efetivamente colegiada e em interação com seus pares. Ao contrário, os incentivos são todos voltados para a preparação em isolamento entre julgadores, desde a condução do processo pelo ministro- relator, passando pela formulação final do voto no seu gabinete antes de apresentá-lo para votação em sessões plenárias ou de turma, pelos eventuais pedidos de vista do processo pelos demais ministros e até o encerramento da votação. Em todas essas etapas a rotina de trabalho apresenta baixo grau de interação entre os ministros, que tendem a se isolar dos demais nos seus gabinetes, para ali formarem sua convicção" (2012, p. 26).
} 


\begin{abstract}
A ausência do relato sistemático da jurisprudência impede que ela seja conhecida tanto em relação ao que nela se contém de decisão quanto de fundamentação já usadas pelo STF. Dessa forma, a própria jurisprudência da Corte (isto é, o conjunto integral de suas decisões) não é fator influente na determinação do resultado e das razões respectivas do novo julgamento. A globalidade do trabalho desenvolvido pelo Tribunal nas ocasiões anteriores não é realmente aproveitada para o desenvolvimento de uma interpretação judicial contínua da Constituição. (SUNDFELD; PINTO, 2012, p. 29).
\end{abstract}

A grande questão é que a jurisprudência não é utilizada pelo Supremo Tribunal Federal como critério para tomada de decisão, mas sim para legitimar a decisão que foi previamente tomada pelo Ministro - o que serve para demonstrar que o STF não valoriza sua própria jurisprudência. ${ }^{7}$ Como afirmam Sundfeld e Pinto: "[o STF] relega a jurisprudência à condição de mero argumento a serviço da tese sustentada pelo voto" $(2012$, p. 31).

Ademais, a falta de sistematização na utilização da jurisprudência leva ainda à dificuldade em se estabelecer, nos dizeres de Sundfeld e Pinto, uma "linha de continuidade", levando assim a uma fragmentação na construção jurisprudencial (2012, p. 34). Tal situação é ainda mais delicada quando se está diante de uma mudança no entendimento jurisprudencial do Tribunal. Afinal, mudanças sem tratamento sistematizado levam a uma fragmentação ainda maior na jurisprudência. Sobre tal situação, Sundfeld e Pinto relatam: "não há o enfrentamento do ônus argumentativo criado pela jurisprudência revertida por meio do afastamento integral das razões até então prevalecentes”, eis que o STF se restringe a fazer uma “menção esporádica a julgados representativos da posição anterior” (2012, p. 37). A conclusão dos mencionados autores é que, “de um modo geral, [...] o STF não dialoga de maneira sincera com seus precedentes" (2012, p. 37).

Após tais considerações, resta examinar alguns exemplos que demonstram como o Supremo Tribunal Federal não valoriza sua jurisprudência - seja em razão da "fundamentação personalista", seja pela "ausência da síntese do estado da jurisprudência". Cabe apenas um esclarecimento: o presente estudo não se propõe a analisar o acerto ou não das decisões do STF que serão a seguir expostas, mas sim qual é o papel da jurisprudência na tomada de tais decisões. É como afirma Mendes (2012, p. 69):

\footnotetext{
7 Afirmam Sundfeld e Pinto (2012, p. 31): “A ausência, muitas vezes, de síntese orgânica do estado da jurisprudência nos acórdãos do STF parece ter ligação com certa característica quanto ao uso dos precedentes pelos seus ministros. A leitura dos votos dos ministros do STF mostra que a invocação de precedentes judiciais não costuma ser feita com o objetivo de avaliar a ação em julgamento dentro de uma corrente jurisprudencial, mas, sim, de utilizá-los como elementos de reforço argumentativo dentro da estratégia de decisão escolhida pelo voto. O conjunto da jurisprudência não é tomado como dado a ser necessariamente considerado independentemente do resultado que o voto venha a defender, inclusive para eventualmente superá-lo, mas como um dos vários elementos que podem ser utilizados para a defesa de um resultado, a depender da sua conveniência".
} 
Deveria preocupar aos observadores da jurisdição constitucional brasileira não somente o que o STF decide (ou o significado que dá ao texto constitucional em cada caso concreto), mas também como ele decide. Na medida em que nos omitimos ou falhamos em fazer essa pergunta, deixamos o STF imune ao acompanhamento crítico de seu estilo decisório. Abrimos mão, assim, da possibilidade de interpelá-lo pelos seus eventuais vícios e de ajudá-lo a reconhecê-los.

\section{A DESVALORIZAÇÃO DA JURISPRUDÊNCIA EM SITUAÇÕES CONCRETAS.}

O presente item pretende demonstrar, por meio da análise de situações concretas, como o Supremo Tribunal Federal não valoriza sua própria jurisprudência.

Inicialmente será examinada a questão do foro por prerrogativa de função no STF, a conexão ou continência com aqueles que não possuem o foro e a faculdade de desmembramento contida no Código de Processo Penal. Será então demonstrado que a jurisprudência do Supremo Tribunal Federal é pelo desmembramento. Entretanto, por ocasião do julgamento de questão de ordem no Inquérito 2.245, o Pleno do STF decidiu de forma contrária a seus precedentes, ou seja, pela reunião.

Tal julgamento exemplificará perfeitamente a "fundamentação personalista", e ainda a ausência de enfrentamento do ônus argumentativo necessário para romper a jurisprudência até então predominante - pelo desmembramento -, o que é característica da "ausência da síntese do estado da jurisprudência".

Em seguida, será demonstrado que, apesar da existência de entendimento sumulado pelo descabimento, no âmbito do STF, de habeas corpus contra indeferimento de liminar, são incontáveis os precedentes que admitem a impetração da ação constitucional. Portanto, a generalização contida na súmula não contém uma regra séria - nos dizeres de Struchiner. Será demonstrado que a utilização ou não da Súmula serve apenas para legitimar a decisão já previamente tomada pelo ministro, e não como critério de tomada de decisão.

\subsection{O foro por prerrogativa de função, a jurisprudência pela reunião e o julgado pelo desmembramento na questão de ordem no Inquérito 2.245.}

A Constituição da República prevê, em seu art. 102, a competência do Supremo Tribunal Federal. No que interessa a este estudo, destaca-se o inc. I, alíneas $b$ e $c$, que preveem as hipóteses de competência originária para processar e julgar acusados de infrações penais. ${ }^{8}$ Trata-se do foro por prerrogativa de função. ${ }^{9}$

\footnotetext{
8 “Art. 102. Compete ao Supremo Tribunal Federal, precipuamente, a guarda da Constituição, cabendo-lhe: I - processar e julgar, originariamente:
} 
É ainda perfeitamente possível - e comum - que existam outros acusados que não se enquadram nas hipóteses de foro por prerrogativa de função previstas na Constituição, mas estejam ligados por conexão ou continência aos detentores de tal foro, conforme preveem os arts. 76 e 77 do Código de Processo Penal. ${ }^{10}$

Merece ainda destaque o art. 79 do CPP, que prevê que "a conexão e a continência importarão unidade de processo e julgamento". ${ }^{11}$ Sendo assim, conclui-se que, havendo um acusado detentor de foto por prerrogativa de função no âmbito do Supremo Tribunal Federal, os demais acusados também devem ser julgados por tal Tribunal - ao menos como regra geral. É o que conclui Oliveira (2012, p. 224): "não vemos maiores dificuldades para a adoção da reunião de processos junto ao foro privativo, para processamento da ação originária" ${ }^{12}$

Isso porque o art. 80 do Código de Processo Penal prevê, de forma facultativa, a separação. A norma prevê um rol exemplificativo de hipóteses que podem levar à separação. ${ }^{13}$ Interessante destacar a hipótese lá prevista relativa ao "excessivo número de acusados".

infrações penais comuns, o Presidente da República, o Vice-Presidente, os membros do Congresso Nacional, seus próprios Ministros e o Procurador-Geral da República;

c) nas infrações penais comuns e nos crimes de responsabilidade, os Ministros de Estado e os Comandantes da Marinha, do Exército e da Aeronáutica, ressalvado o disposto no art. 52, I, os membros dos Tribunais Superiores, os do Tribunal de Contas da União e os chefes de missão diplomática de caráter permanente;”.

A redação da alínea $c$ foi dada pela Emenda Constitucional n. 23. (BRASIL, 1988)

${ }^{9}$ Há previsão na Constituição de foro por prerrogativa de função em vários outros tribunais. Entretanto, o presente estudo limitará sua análise ao Supremo Tribunal Federal. Optou-se pela expressão "foro por prerrogativa de função", por sua maior precisão técnica, e não "foro privilegiado", como comumente se lê.

10 “Art. 76. A competência será determinada pela conexão:

I - se, ocorrendo duas ou mais infrações, houverem sido praticadas, ao mesmo tempo, por várias pessoas reunidas, ou por várias pessoas em concurso, embora diverso o tempo e o lugar, ou por várias pessoas, umas contra as outras;

II - se, no mesmo caso, houverem sido umas praticadas para facilitar ou ocultar as outras, ou para conseguir impunidade ou vantagem em relação a qualquer delas;

III - quando a prova de uma infração ou de qualquer de suas circunstâncias elementares influir na prova de outra infração.

Art. 77. A competência será determinada pela continência quando:

I -duas ou mais pessoas forem acusadas pela mesma infração;

II -no caso de infração cometida nas condições previstas nos arts. 51, §1\% $\frac{\text { o }}{7}$, segunda parte, e 54 do Código Penal." (BRASIL, 2011)

${ }^{11}$ Há exceções, que ultrapassam o objeto deste estudo. Apenas a título de informação, prevê a norma que não haverá unidade de processo e julgamento "no concurso entre a jurisdição comum e a militar" e "no concurso entre a jurisdição comum e a do juízo de menores", conforme dispositivos contidos nos incs. I e II do mencionado art. 79 do CPP. Os parágrafos de tal artigo ainda dispõem:

"§ $1^{\text {o }}$ Cessará, em qualquer caso, a unidade do processo, se, em relação a algum co-réu, sobrevier o caso previsto no art. 152.

$\S 2^{\circ}$ A unidade do processo não importará a do julgamento, se houver co-réu foragido que não possa ser julgado à revelia, ou ocorrer a hipótese do art. 461". (BRASIL, 2011)

12 Esta também é a posição de Tourinho Filho (2009, p. 170), Lopes Jr. (2013, p. 494-495) e Feitoza (2008, p. 326).

13 “Art. 80. Será facultativa a separação dos processos quando as infrações tiverem sido praticadas em circunstâncias de tempo ou de lugar diferentes, ou, quando pelo excessivo número de acusados e para não lhes prolongar a prisão provisória, ou por outro motivo relevante, o juiz reputar conveniente a separação.” (BRASIL, 2011) 
Mesma sendo a separação possível, de forma facultativa, as normas legais acima mencionadas preveem que a regra geral deva ser a reunião, e somente excepcionalmente a separação. ${ }^{14}$ Em 2003, o Supremo Tribunal Federal chegou inclusive a editar a Súmula 704, que afirma: "não viola as garantias do juiz natural, da ampla defesa e do devido processo legal a atração por continência ou conexão do processo do co-réu ao foro por prerrogativa de função de um dos denunciados".

Por outro lado, é perfeitamente possível afirmar que a jurisprudência do Supremo Tribunal Federal se firmou no sentido do desmembramento. São numerosos os julgados que separaram os detentores de foro por prerrogativa de função no STF daqueles que não o possuem. ${ }^{15}$ A mero título exemplificativo, menciona-se o seguinte:

“AÇÃO PENAL. QUESTÃO DE ORDEM. DESMEMBRAMENTO DO FEITO. ART. 80 DO CPP. APLICABILIDADE, NA HIPÓTESE. PRECEDENTES. QUESTÃO DE ORDEM ACOLHIDA, PARA QUE SEJAM APURADOS NESSA CORTE SOMENTE OS FATOS IMPUTADOS AO ACUSADO COM PRERROGATIVA DE FORO NO SUPREMO TRIBUNAL FEDERAL. 1. O presente caso conta com 10 (dez) denunciados e, na data de hoje, com 78 (setenta e oito) volumes e mais 15 (quinze) apensos, o que demonstra a inviabilidade do processo e julgamento de tantos acusados por essa Corte e constitui razão mais do que suficiente para autorizar o desmembramento do feito, pois apenas um dos acusados detém a prerrogativa de foro prevista no artigo 102, inciso I, alínea "b", da Constituição Federal. 2. A doutrina e a jurisprudência são uníssonas no sentido de aplicar o art. 80 do Código de Processo Penal nos processos criminais em que apenas um ou alguns dos acusados detêm a prerrogativa de foro. 3. Não há, no caso, qualquer excepcionalidade que impeça a aplicação

\footnotetext{
$\overline{14}$ Ainda que não seja o tema tratado neste estudo, é o caso de se mencionar a hipótese de crime doloso contra a vida praticado por quem possui foro por prerrogativa de função em concurso com acusado que não a possui. Em tal situação, o entendimento é pela necessidade de separação. Aquele que não possuir o foro por prerrogativa deve ser julgado pelo Tribunal do Júri, respeitando-se assim o art. $5^{\circ}$, XXXVIII, $d$, da Constituição. Nesse sentido é a posição defendida por Lopes Jr. (2013, p. 488), Oliveira (2012, p. 220) e Feitoza (2008, p. 326). Já o Supremo Tribunal Federal não possui entendimento absolutamente pacificado. Há precedentes do Pleno e da $1^{\text {a }}$ Turma nesse sentido: HC 69325, Relator(a): Min. NÉRI DA SILVEIRA, Relator(a) p/ Acórdão: Min. MARCO AURÉLIO, Tribunal Pleno; e HC 70581, Relator(a): Min. MARCO AURÉLIO, Segunda Turma. A $2^{\text {a }}$ Turma já decidiu de forma diversa: HC 83583, Relator(a): Min. ELLEN GRACIE, Segunda Turma. Oliveira (2012, p. 221) afirma que "o Supremo Tribunal Federal tem jurisprudência firme no sentido da separação obrigatória dos processos". Já Lopes Jr. (2013, p. 488) reconhece que "a matéria não é pacífica" no âmbito do STF.

15 Inq 2628 QO, Relator(a): Min. CÁRMEN LÚCIA, Tribunal Pleno, julgado em 30/04/2008, DJe-182 DIVULG 25-09-2008 PUBLIC 26-09-2008; Inq 2706 AgR, Relator(a): Min. MENEZES DIREITO, Tribunal Pleno, julgado em 14/08/2008, DJe-182 DIVULG 25-09-2008 PUBLIC 26-09-2008; AP 351, Relator(a): Min. MARCO AURÉLIO, Primeira Turma, julgado em 12/08/2004; HC 91347 MC, Relator(a): Min. MARCO AURÉLIO, Tribunal Pleno, julgado em 20/06/2007, DJe-101 DIVULG 13-09-2007 PUBLIC 14-09-2007 DJ 14-09-2007 PP-00032; HC 91347 MC, Relator(a): Min. MARCO AURÉLIO, Tribunal Pleno, julgado em 20/06/2007, DJe-101 DIVULG 13-09-2007 PUBLIC 14-09-2007 DJ 14-09-2007 PP-00032; HC 91174 MC, Relator(a): Min. MARCO AURÉLIO, Tribunal Pleno, julgado em 20/06/2007, DJe-106 DIVULG 20-09-2007 PUBLIC 21-09-2007 DJ 21-09-2007 PP-00020; Pet 2020 QO, Relator(a): Min. NÉRI DA SILVEIRA, Tribunal Pleno, julgado em 08/08/2001, DJ 31-08-2001 PP-00037; dentre outros. Foram aqui mencionados apenas alguns dos julgados, ainda assim apenas aqueles tidos como mais recentes, ou seja, já a partir deste século. O acórdão da questão de ordem no Inquérito 2245 , que será abordado infra, menciona, além de alguns dos julgados acima, vários outros no mesmo sentido, contemporâneos e também anteriores. (Acórdão disponível em http://redir.stf.jus.br/paginadorpub/paginador.jsp?docTP=AC\&docID=494486. Acesso em:20 nov. 2013).
} 
do artigo 80 do CPP. 4. Questão de ordem acolhida, para que sejam apurados nessa Corte somente os fatos imputados ao Deputado Federal envolvido, extraindo-se cópias dos elementos a ele relacionados para autuação de um novo inquérito. Baixa dos autos quanto aos demais acusados." (Inq 2443 QO, Relator(a): Min. JOAQUIM BARBOSA, Tribunal Pleno, julgado em 01/07/2008, DJe-182 DIVULG 25-09-2008 PUBLIC 26-09-2008)

É o caso de se mencionar ainda que a jurisprudência chega a ser tão pacificada nesse sentido que há casos inclusive de desmembramento feito através de decisão monocrática de Ministro Relator, como ocorreu, e.g., no Inquérito $2280 .{ }^{16}$

Neste ponto cabe o primeiro registro: a legislação processual penal prevê que a regra geral é a reunião de acusados, ainda que somente um deles possua foro por prerrogativa de função no Supremo Tribunal Federal. Tanto é assim que chegou a ser criada a mencionada Súmula 704. O desmembramento deve ser a exceção.

Por outro lado, os casos que chegaram ao STF na última década culminaram com o desmembramento. $\mathrm{O}$ que deveria ser exceção se tornou regra, apesar da previsão em sentido contrário do Código de Processo Penal.

Apesar de a jurisprudência ter sido firmada no sentido do desmembramento, ela foi ignorada por ocasião do julgamento de questão de ordem no Inquérito 2.245 , em que se tinha quarenta denunciados. ${ }^{17}$ Tal precedente merece ser analisado, em razão da sua relevância, da grande repercussão e, principalmente, por ter ignorado a jurisprudência consagrada anteriormente - sem, entretanto, enfrentar o ônus argumentativo exigido.

A questão foi submetida a julgamento através de uma questão de ordem, e ocorreu após o oferecimento da denúncia - que envolvia quarenta denunciados -, mas antes de seu recebimento parcial. $^{18}$ Num primeiro momento, o Ministro Relator, Joaquim Barbosa, manifestou-se pelo desmembramento, inclusive mencionando vários precedentes do próprio STF em tal sentido. Em seguida, a Ministra Carmen Lúcia abriu divergência, afirmando: "não encontrei [...] qualquer dado que pudesse provar, jurídica e objetivamente, a conveniência prevista no artigo 80, na parte final do Código de Processo Penal...”. Entretanto, o ponto que mais chama a atenção em seu voto é o seguinte:

\footnotetext{
${ }_{16}$ Relator Min. JOAQUIM BARBOSA, julgado em 11/05/2009, publicado em DJe-095 DIVULG 22/05/2009 PUBLIC 25/05/2009. Trata-se do caso que ficou conhecido pela alcunha de "mensalão mineiro", envolvendo acusações de supostas irregularidades na arrecadação de verbas para a campanha de reeleição de Eduardo Azeredo para o governo de Minas Gerais em 1998.

${ }^{17}$ Cf. nota 1.

${ }^{18} \mathrm{O}$ recebimento parcial da denúncia se refere ao seguinte julgado: Inq 2245, Relator Ministro Joaquim Barbosa, Tribunal Pleno, julgado em 28/08/2007, DJe-139, divulgação em 08/11/2007, publicação em 09/11/2007. Inteiro teor do acórdão disponível em http://redir.stf.jus.br/paginadorpub/paginador.jsp?docTP=AC\&docID=494478. Acesso em 20/11/2013.
} 
O rigor que se impõe a este caso, o qual me parece específico, muito peculiar da história brasileira e que, pela sua só notícia, independentemente de comprovação, agravou a sociedade brasileira da forma como aconteceu, não pode prescindir do conhecimento, da apreciação e do julgamento deste todo como um conjunto que tem uma essência substancial, portanto, entre os fatos inextrincáveis.

Percebe-se desde logo como a "ausência da síntese do estado da jurisprudência", nos dizeres de Sundfeld e Pinto, é manifesta no voto da Ministra Carmen Lúcia. Afinal, ela não enfrentou as razões que até então predominavam na jurisprudência do STF. Apesar dos vários precedentes aplicarem a faculdade do art. 80 do CPP, que permite o desmembramento, o voto não "encontrou" motivos para aplicação da referida norma - utilizando-se aqui o mesmo verbo utilizado pela Ministra. O que deveria ter se verificado seria o enfrentamento direto do ônus argumentativo para que se superasse o entendimento jurisprudencial até então consagrado.

Ademais, percebe-se também certo casuísmo, o que leva a um decisionismo infundado. Afinal, o voto decidiu pela reunião em razão de uma alegada "peculiaridade" do caso na história brasileira - como se notícias de corrupção, até mesmo no primeiro escalão do governo federal, nunca tivessem sido veiculadas. Mais uma vez registra-se: não se está fazendo juízo de valor acerca do mérito da decisão, pois não é o objeto do presente trabalho. Pretende-se, somente, evidenciar a ausência de preocupação do Supremo Tribunal Federal ao negar sua própria jurisprudência.

Enfim, a divergência aberta pelo voto da Ministra Carmem Lúcia revela como o Supremo Tribunal Federal não valoriza sua própria jurisprudência.

O julgamento se seguiu com os Ministros Lewandowski, Carlos Britto, Cezar Peluso e Marco Aurélio acompanhando o Relator. Já os Ministros Eros Grau, Gilmar Mendes, Celso de Mello e Ellen Gracie seguiram a divergência iniciada pela Ministra Carmem Lúcia. O Ministro Sepúlveda Pertence proferiu voto médio, pelo desmembramento parcial.

Ou seja, num primeiro momento, cinco ministros defendendo determinada posição (a aplicação da jurisprudência predominante), cinco defendendo outra, e um com uma posição intermediária.

É nesse contexto que assiste razão a Mendes (2010a) ao afirmar: “....argumentos 'do tribunal' quase nunca existem, exceto por obra de uma metáfora. Não há, exceções à parte, razões compartilhadas pela maioria dos ministros, razões que, boas ou ruins, pudéssemos generalizar como do tribunal". ${ }^{19} \mathrm{O}$ autor fala ainda em tribunal "descolegiado" ao se referir ao

\footnotetext{
${ }^{19}$ Ressalte-se que tal análise de Mendes é abstrata, e em momento algum se refere ao julgamento da questão de ordem no Inquérito 2245, ora em exame. Entretanto, suas colocações são inteiramente aplicáveis.
} 
Supremo Tribunal Federal, razão pela qual intitula sua análise de "onze ilhas". ${ }^{20}$ É o que ocorreu num primeiro momento.

Já num segundo momento, após discussões sobre a viabilidade de um desmembramento parcial, na forma sugerida pelo Ministro Sepúlveda Pertence, acaba prevalecendo a posição pela reunião de todos os denunciados, vencidos apenas os Ministros Sepúlveda Pertence e Marco Aurélio. O julgado recebeu a seguinte ementa:

\begin{abstract}
QUESTÃO DE ORDEM. INQUÉRITO. DESMEMBRAMENTO. ARTIGO 80 DO CPP. CRITÉRIO SUBJETIVO AFASTADO. CRITÉRIO OBJETIVO. INADEQUAÇÃO AO CASO CONCRETO. MANUTENÇÃO INTEGRAL DO INQUÉRITO SOB JULGAMENTO DA CORTE. Rejeitada a proposta de adoção do critério subjetivo para o desmembramento do inquérito, nos termos do artigo 80 do CPP, resta o critério objetivo, que, por sua vez, é desprovido de utilidade no caso concreto, em face da complexidade do feito. Inquérito não desmembrado. Questão de ordem resolvida no sentido da permanência, sob a jurisdição do Supremo Tribunal Federal, de todas as pessoas denunciadas." (Inq 2245 QO-QO, Relator(a): Min. JOAQUIM BARBOSA, Tribunal Pleno, julgado em 06/12/2006, DJe-139 DIVULG 08-11-2007 PUBLIC 09-11-2007 DJ 09-11-2007 PP-00043)
\end{abstract}

Analisando-se a íntegra do acórdão ${ }^{21}$, percebe-se que, após o voto médio do Ministro Sepúlveda Pertence, o Tribunal chegou a um impasse, eis que não houve consenso sobre qual seria o critério para um desmembramento parcial. Após se chegar à conclusão que não haveria tal critério, os Ministros decidiram pela reunião, conforme a ementa acima.

Um último aspecto deve ser novamente considerado, relativo à "ausência da síntese do estado da jurisprudência". Enquanto os votos que decidiram pelo desmembramento

20 Em outra análise, Mendes trata do julgamento pelo Supremo Tribunal Federal envolvendo a constitucionalidade da chamada Lei da Ficha Limpa envolvendo o processo eleitoral então em curso. Trata-se de mais um exemplo envolve a completa ausência de deliberação colegiada. Afirma Mendes que o julgamento durou quatorze horas, acrescentando: "a importância e a urgência do caso dispensam comentários. O tribunal nos respondeu o seguinte: cinco ministros acham que sim, cinco acham que não. Como uma cadeira estava vaga, não houve como desempatar. Sem decisão, o caso foi arquivado" (2010b). E conclui: "Talvez essas 14 horas tenham sido gastas num profundo debate, no qual, após intensa troca de argumentos e um esforço sincero para digerir as posições em jogo, cada ministro, apesar de tentar, não se convenceu. Preferiu abraçar-se a seu voto, que, a propósito, trouxe pronto do seu gabinete. Na minha opinião, não foi isso o que vimos. Fomos expostos a 14 horas de uma sonolenta sessão de leitura. Era o texto escrito, não o ministro, que participava daquela sessão. Construímos um tribunal no qual o encontro entre os juízes passou a ser a parte menos importante do seu processo decisório. [...] Não se espera que uma corte, numa sociedade pluralista, alcance o consenso. O desacordo pode mostrar a vitalidade da discussão e a complexidade do tema. Em muitas cortes do mundo, votos vencidos são evidências da qualidade da deliberação, não o contrário. São bem-vindos para o arejamento da argumentação jurídica. A pluralidade de votos do STF, porém, indica fenômeno diverso. Enraizou-se, ali, um excessivo apego à autoria individual e um desinteresse em produzir votos coletivos. A boa técnica judicial pede, no entanto, desapego. Situações extremas podem resultar num impasse. O que vimos nesse caso não foi uma situação extrema, mas cotidiana. Por azar, não havia ninguém para desempatar. Tamanha irracionalidade se naturalizou no dia a dia da Casa. Ao contrário do que se disse, o STF é também responsável pelo impasse. O tribunal precisa repensar seu modo de decidir" (2010b). A situação descrita por Mendes, bem como sua análise, também se aplica ao julgamento da questão de ordem no Inquérito 2245.

21 Para mais detalhes sobre o julgado, cf. a íntegra do acórdão, disponível em http://redir.stf.jus.br/paginadorpub/paginador.jsp?docTP=AC\&docID=494486. Acesso em 20 jul. 2015. 
invocaram os vários precedentes em tal sentido, os demais se revelaram muito mais superficiais e simplistas. Isso porque não enfrentaram diretamente os argumentos já consagrados pela jurisprudência dominante, demonstrando uma vez mais a desvalorização da jurisprudência do STF pelo próprio Tribunal.

\subsection{A Súmula 691 e os precedentes em sentido contrário.}

Enquanto o item anterior tratou de exemplificar, num caso concreto, a "fundamentação personalista" e, com relação à "ausência da síntese do estado da jurisprudência", o não enfrentamento do ônus argumentativo na mudança de entendimento jurisprudencial, o presente tópico ilustrará como a jurisprudência não é utilizada pelo Supremo Tribunal Federal como critério para tomada de decisão, mas sim para corroborar a decisão já previamente tomada pelo Ministro.

Antes de apresentar os exemplos que comprovam a tese de Sundfeld e Pinto, é necessário registrar que o STF, em 2003, editou a Súmula 691, criada com o intuito de impedir a impetração de habeas corpus no referido Tribunal questionando indeferimento de liminar. A redação da Súmula é a seguinte: "não compete ao Supremo Tribunal Federal conhecer de habeas corpus impetrado contra decisão do Relator que, em habeas corpus requerido a tribunal superior, indefere a liminar".

O fundamento da súmula 691 consiste em evitar a supressão de instância. Para que o Supremo Tribunal Federal possa avaliar a legalidade do indeferimento de uma liminar tem, necessariamente, de se pronunciar sobre a eventual procedência das questões de direito articuladas no mérito do Habeas que teve a liminar indeferida.

A liminar em Habeas Corpus é fruto de uma construção jurisprudencial. Como qualquer liminar, para ser concedida, deve reunir os requisitos do periculum in mora e o fumus boni iuris. É exatamente a análise do fumus boni iuris que compromete a viabilidade de um Habeas impetrado contra indeferimento da liminar de outro Habeas.

Além da impossibilidade de suprimir instância, a súmula 691 é um importante instrumento para limitar a quantidade de ações de habeas corpus a tramitarem no Supremo Tribunal Federal. Oliveira (2012, p. 940) afirma que a Súmula foi criada "na tentativa de coibir o uso exacerbado do writ nessas circunstâncias e evitar a supressão de instância”.

Em que pese a existência da Súmula 691, são numerosos os precedentes em sentido contrário, ou seja, que admitem o habeas corpus perante o Supremo Tribunal Federal em 
casos de indeferimento de liminar por tribunal superior quando for manifesta a coação ilegal atravessada pelo paciente. ${ }^{22}$ A seguinte ementa exemplifica a possibilidade de superação da Súmula quando o constrangimento for "flagrante":

\begin{abstract}
"HABEAS CORPUS - OBJETO - INDEFERIMENTO DE LIMINAR EM IDÊNTICA MEDIDA - VERBETE 691 DA SÚMULA DO SUPREMO TRIBUNAL FEDERAL. A Súmula do Supremo Tribunal Federal revela, como regra, o não-cabimento do habeas contra ato de relator que, em idêntica medida, haja implicado o indeferimento de liminar. A exceção corre à conta de flagrante constrangimento ilegal que, uma vez não verificado, impede a sequiência do habeas corpus" (HC 84014 AgR, Relator(a): Min. MARCO AURÉLIO, Primeira Turma, julgado em 30/03/2004, DJ 25-062004 PP-00017).
\end{abstract}

Cabe ainda destacar que há precedentes que também superam a Súmula mesmo se tratando de habeas corpus que não discutiam ofensa direta à liberdade de locomoção, ou seja, com paciente preso, mas sim ofensas indiretas, como casos envolvendo, por exemplo, reconhecimento de nulidades, trancamento de ação penal e indiciamento em inquérito policial. $^{23}$

Ainda que não se trate de súmula vinculante ${ }^{24}$, chama a atenção como há precedentes do próprio Supremo Tribunal Federal ignorando o entendimento sumulado. A questão aqui

22 HC 86864 MC, Relator(a): Min. CARLOS VELlOSO, Tribunal Pleno, julgado em 20/10/2005, DJ 16-122005 PP-00059; HC 100395, Relator(a): Min. GILMAR MENDES, Segunda Turma, julgado em 29/06/2010, DJe149 DIVULG 12-08-2010 PUBLIC 13-08-2010; HC 97998, Relator(a): Min. EROS GRAU, Segunda Turma, julgado em 23/06/2009, DJe-157 DIVULG 20-08-2009 PUBLIC 21-08-2009; HC 91183, Relator(a): Min. RICARDO LEWANDOWSKI, Primeira Turma, julgado em 12/06/2007, DJe-047 DIVULG 28-06-2007 PUBLIC 2906-2007 DJ 29-06-2007 PP-00059; HC 87032, Relator(a): Min. MARCO AURÉLIO, Primeira Turma, julgado em 19/02/2008, DJe-055 DIVULG 27-03-2008 PUBLIC 28-03-2008; HC 118935, Relator(a): Min. RICARDO LEWANDOWSKI, Segunda Turma, julgado em 26/11/2013, PROCESSO ELETRÔNICO DJe-241 DIVULG 06-12-2013 PUBLIC 09-12-2013; HC 118494, Relator(a): Min. ROBERTO BARROSO, Primeira Turma, julgado em 26/11/2013, PROCESSO ELETRÔNICO DJe-243 DIVULG 10-12-2013 PUBLIC 11-12-2013; HC 117796, Relator(a): Min. DIAS TOFFOLI, Primeira Turma, julgado em 08/10/2013, PROCESSO ELETRÔNICO DJe-218 DIVULG 04-112013 PUBLIC 05-11-2013; HC 115738, Relator(a): Min. ROSA WEBER, Primeira Turma, julgado em 03/09/2013, PROCESSO ELETRÔNICO DJe-182 DIVULG 16-09-2013 PUBLIC 17-09-2013; HC 115795, Relator(a): Min. GILMAR MENDES, Segunda Turma, julgado em 04/06/2013, PROCESSO ELETRÔNICO DJe-240 DIVULG 0512-2013 PUBLIC 06-12-2013; HC 112889, Relator(a): Min. CÁRMEN LÚCIA, Segunda Turma, julgado em 12/03/2013, PROCESSO ELETRÔNICO DJe-057 DIVULG 25-03-2013 PUBLIC 26-03-2013; HC 103362, Relator(a): Min. CELSO DE MELLO, Segunda Turma, julgado em 06/03/2012, ACÓRDÃO ELETRÔNICO DJe-230 DIVULG 22-11-2012 PUBLIC 23-11-2012; dentre vários outros.

3 HC 85185, Relator(a): Min. CEZAR PELUSO, Tribunal Pleno, julgado em 10/08/2005, DJ 01-09-2006 PP00018; HC 115015, Relator(a): Min. TEORI ZAVASCKI, Segunda Turma, julgado em 27/08/2013, PROCESSO ELETRÔNICO DJe-179 DIVULG 11-09-2013 PUBLIC 12-09-2013; HC 108795, Relator(a): Min. CÁRMEN LÚCIA, Primeira Turma, julgado em 03/04/2012, PROCESSO ELETRÔNICO DJe-150 DIVULG 31-072012 PUBLIC 01-08-2012; (HC 108337, Relator(a): Min. DIAS TOFFOLI, Primeira Turma, julgado em 14/02/2012, PROCESSO ELETRÔNICO DJe-054 DIVULG 14-03-2012 PUBLIC 15-03-2012; dentre vários outros.

24 A súmula vinculante é prevista no art. 103-A, criado pela Emenda Constitucional n. 45, e assim dispõe em seu caput: "O Supremo Tribunal Federal poderá, de ofício ou por provocação, mediante decisão de dois terços dos seus membros, após reiteradas decisões sobre matéria constitucional, aprovar súmula que, a partir de sua publicação na imprensa oficial, terá efeito vinculante em relação aos demais órgãos do Poder Judiciário e à administração pública direta e indireta, nas esferas federal, estadual e municipal, bem como proceder à sua revisão ou cancelamento, na forma estabelecida em lei".

Revista de Argumentação e Hermenêutica Jurídica | e-ISSN: 2526-0103 | Minas Gerais | v. 1 | n. 2 | p. $27-43$ | Jul/Dez. 
posta envolve o questionamento de como se pode conciliar a existência de uma Súmula e ainda de tantos julgados que a contrariam.

Não se pode negar que as súmulas envolvem entendimentos generalizados, ou seja, generalizações. Struchiner (2010, p. 109) afirma: “apesar de as generalizações serem apenas probabilísticas, não acarretando necessariamente os objetivos (justificação) da regra, ainda assim são fundamentais para o bom andamento da nossa linguagem crítica”, acrescentando ainda que não é possível que as generalizações apresentem verdades universais. Sendo assim, acabam sendo sobreinclusivas ou subinclusivas (2010, p. 110). ${ }^{25}$

Aplicando-se a lição acima ao exemplo em análise, é possível afirmar que as súmulas não deverão ser consideradas em necessariamente todos os casos em julgamento. Caso contrário, teríamos uma verdade universal. Entretanto, o que está em questão é como a Súmula é contrariada reiteradamente pelo próprio STF, e não apenas excepcionalmente. É nesse contexto que, continuando sua análise, Struchiner coloca que a regra só seria "séria" quando fosse "capaz de oferecer alguma resistência às exigências da justificação da regra que caminham em um sentido contrário" (2010, p. 112). Isso porque "uma regra séria eleva o patamar de força necessário para que ela seja derrotada" (2010, p. 113).

Ocorre que os julgados mencionados não contêm um "patamar de força" destacada para superar o entendimento sumulado. Pelo contrário: eles se restringem a afirmar que há "flagrante" constrangimento, ou "manifesto", ou "evidente", sem maiores considerações. A ausência de um critério objetivo somada à despreocupação do STF em fundamentar o afastamento, no caso concreto, da súmula 691 torna ainda mais evidente a procedência da tese defendida no presente artigo: as decisões da Suprema Corte tem caráter personalista.

Tal constatação leva a duas conclusões: inicialmente, tem-se que a Súmula 691 não oferece "resistência" aos julgados que a ignoram, ou seja, não "eleva o patamar" de força para que ela seja superada - utilizando o vocabulário de Struchiner.

Além disso, serve para demonstrar que a Súmula só é utilizada quando o julgador já profere um pré-julgamento pelo descabimento do habeas corpus. Ou seja, simplesmente para legitimar a decisão anteriormente tomada, e não como critério de tomada de decisão. Isso porque, caso o ministro entenda que é o caso de concessão da ação constitucional, basta afirmar que o constrangimento é flagrante, ou manifesto, ou evidente, ou algo do gênero.

\footnotetext{
${ }^{25}$ Conceitua o autor: "uma regra é sobreinclusiva quando seu predicado fático engloba casos particulares que não geram a consequências que representa a justificação da regra. [...] Por outro lado, os mesmos predicados fáticos são também subinclusivos, já que deixam de tratar de certos casos que acarretam a consequência que representa a justificação da regra" (2010, p. 109-110).
} 
Caso a Súmula fosse séria - nos dizeres de Struchiner -, imporia um ônus argumentativo destacado para que fosse superada. Ou seja, a construção jurisprudencial do Supremo Tribunal serve apenas para legitimar a decisão do ministro, já previamente tomada, pelo indeferimento do habeas corpus. Por outro lado, se o ministro entender pela concessão, não são necessários maiores esforços argumentativos.

Por tudo o que foi dito é que a conclusão de Struchiner se aplica ao exemplo em análise:

Regras são relações entre agentes e linguagem. A escolha por calibrar reiteradamente as generalizações do direito de acordo com os seus propósitos subjacentes, operando como um alfaiate da linguagem jurídica, é incompatível com a existência de regras... (STRUCHINER, 2010, p. 126).

O que o Supremo Tribunal Federal tem feito, com relação à Súmula 691, é aplicá-la (ou não) de acordo com "propósitos subjacentes", "calibrando" o seu entendimento jurisprudencial da forma como lhe parece mais conveniente. Portanto, opera-se como um "alfaiate da linguagem", e isso é "incompatível com a existência de regras". ${ }^{26}$

\section{CONSIDERAÇÕES FINAIS}

O presente estudo, num primeiro momento, tratou de apresentar a posição de Sundfeld e Pinto, acerca da "fundamentação personalista" e da "ausência da síntese do estado da jurisprudência" no âmbito do Supremo Tribunal Federal, bem como o "projeto de corte deliberativa" de Mendes, em uma crítica ao processo de tomada de decisão no STF.

Em seguida, foram apresentadas duas situações concretas que demonstram tais ideias: o julgamento de questão de ordem do Inquérito 2.245 (que contrariou a jurisprudência existente, pelo desmembramento) e ainda a Súmula 691, que é ignorada em incontáveis precedentes - sendo tal análise baseada em considerações de Struchiner sobre generalizações e regras sérias.

Tais situações revelam como o Supremo Tribunal Federal não valoriza sua própria jurisprudência, além de demonstrar como são tomadas as decisões.

\footnotetext{
${ }^{26}$ Como já foi dito ao final do item 2, o presente estudo não tem como objeto examinar a correção ou não dos julgados do Supremo Tribunal Federal, mas sim demonstrar como a jurisprudência do STF é desvalorizada pelo próprio Tribunal. Entretanto, é necessário registrar, ainda que de forma sucinta, o desacerto da Súmula 691. Isto porque o fato de diminuir a quantidade de habeas corpus no Supremo Tribunal Federal e ainda evitar supressão de instância, que são os fundamentos da criação da Súmula (Oliveira, 2012, p. 940), não podem se sobrepor à relevância constitucional dada à proteção da liberdade (art. $5^{\circ}$, caput) e à própria ação de habeas corpus (art. $5^{\circ}$, LXVIII). Tourinho Filho também se mostra contrário à Súmula 691 (2008, p. 617-620).
} 
Há necessidade de se reverter tal processo. Como afirmam Sundfeld e Pinto, a jurisprudência deve

\begin{abstract}
ser tratada com o valor normativo que possui e receber análise judicial refinada em função da decisão que representa e dos argumentos que contém. Para isso, também é preciso repensar o próprio modo de decidir do STF. Reformas devem ocorrer no processo decisório para que o tratamento adequado de precedentes seja viabilizado (SUNDFELD; PINTO, 2012, p. 39-40).
\end{abstract}

A reforma no processo decisório, em nossa opinião, não é legislativa ou regimental. Passa pela gestação do voto e da decisão colegiada. O juiz não deve decidir e, só depois, buscar, nos precedentes, uma justificativa. $\mathrm{O}$ voto deve ser construído a partir dos precedentes. A tomada de decisão não se dá na solidão do gabinete de cada ministro, mas sim no colegiado. As sessões de julgamento do Supremo Tribunal Federal, bem como de qualquer outro tribunal, deve servir para construir a decisão colegiada a partir do debate dos fundamentos dos votos individuais.

\title{
REFERÊNCIAS
}

DAVID, René. Os grandes sistemas do direito contemporâneo. São Paulo: Martins Fontes, 2002.

FEITOZA, Denilson. Direito processual penal (teoria, crítica e práxis). 5. ed. Niterói: Impetus, 2008.

LOPES JR., Aury. Direito processual penal. 10. ed. São Paulo: Saraiva, 2013.

MENDES, Conrado Hübner. O projeto de uma corte deliberativa. In: VOJVODIC, Adriana et al. (orgs.). Jurisdição Constitucional no Brasil. São Paulo: Malheiros, 2012.

MENDES, Conrado Hübner. Onze ilhas. Folha de S. Paulo 1 fev. 2010a. Disponível em: http://www1.folha.uol.com.br/fsp/opiniao/fz0102201008.htm. Acesso em: 22 jul. 2015.

MENDES, Conrado Hübner. Sessão de leitura no STF. Folha de S. Paulo 5 out. 2010b. Disponível em: http://www1.folha.uol.com.br/fsp/opiniao/fz0510201007.htm. Acesso em: 22/07/2015.

OLIVEIRA, Eugênio Pacelli. Curso de processo penal. 16. ed. São Paulo: Atlas, 2012.

STRUCHINER, Noel. O direito como um campo de escolhas: por uma leitura das regras como relações. In: Rodriguez, José Rodrigo et al. (orgs.). Nas fronteiras do formalismo. A função social da dogmática jurídica hoje. São Paulo, Saraiva, 2010. 
SUNDFELD, Carlos Ari; PINTO, Henrique Motta. Três desafios para melhorar a jurisdição constitucional brasileira. In: VOJVODIC, Adriana et al. (orgs.). Jurisdição Constitucional no Brasil. São Paulo: Malheiros, 2012.

TOURINHO FILHO, Fernando da Costa. Processo penal. 31. ed. São Paulo: Saraiva, 2009, V. III.

TOURINHO FILHO, Fernando da Costa. Processo penal. 30. ed. São Paulo: Saraiva, 2008, V. IV.

Vade Mecum RT. $6^{\text {a }}$ Ed. São Paulo: Editora Revista dos Tribunais, 2011. 